\title{
Exploring Taiwanese Students' Perceptions of Active Explicit Vocabulary Instruction: A Case Study in an English Medium Course
}

\author{
I-Chia Chou* \\ Wenzao Ursuline University of Languages, Taiwan \\ Corresponding author: I-Chia Chou, E-mail: 98034@mail.wzu.edu.tw
}

\section{ARTICLE INFO}

Article history

Received: January 10, 2018

Accepted: January 25, 2018

Published: January 31, 2018

Volume: 6 Issue: 1

Conflicts of interest: None

Funding: None

\begin{abstract}
Vocabulary knowledge is considered important in second and foreign language learning because learners' insufficient vocabulary has been consistently reported as a significant problem in their achievement of second-language (L2) learning. Despite of numerous vocabulary studies, few of them have implemented a learner-centered and interactive approach. The current study attempted to implement an interactive explicit vocabulary instruction in an English-medium course in Taiwan. Students' attitudes and perceptions on the implementation were explored. Data were collected using both quantitative and qualitative methods via questionnaires and interviews. Fifty-six students participated in this study. The results showed that students had positive attitudes toward this approach. In addition, students' interview feedback demonstrated the most and least appreciated aspects of this approach. Educational and pedagogical suggestions for English-as-a-Foreign-Language (EFL) teachers were given.
\end{abstract}

Key words: Active Learning, Vocabulary Instruction, English-Medium Instruction, EFL, Undergraduate Students

\section{INTRODUCTION}

Vocabulary knowledge is considered important in second-language acquisition and foreign-language learning because the insufficient vocabulary of the learners has been reported as a critical problem in their achievements of L2 learning (Kojic-Sabo \& Lightbown, 1999; Richards, 2002). Previous studies also pointed out that limited knowledge of academic vocabulary has been associated with academic failure (Anjomshoa \& Zamanian, 2017; Hiebert \& Lubliner, 2008; Masrai \& Milton, 2018). Knudsen and Westbrook (2013) claimed that the acquisition of academic vocabulary seems to be a fundamental skill that will lead to success in reading, listening, and other skills in English-medium classes. Students in Hsieh and Kang's (2007) study reported that their vocabulary was inadequate for English-medium instruction (EMI) lecture comprehension. Consistent with the findings of Chia, Johnson, Chia and Olive (1999) and Evans and Green (2007), among the many problems causing students' reading difficulties, limited vocabulary and slow reading speed were the most frequently reported (p. 71). The findings show a link between EMI lecture comprehension and academic vocabulary acquisition. Without sufficient vocabulary, students suffer greatly in their lectures and reading comprehension.

Many studies have thus focused on how to maximize English-language learners' vocabulary knowledge and learning. Vocabulary learning and teaching research has followed two main approaches: explicit learning and incidental learning.
Explicit vocabulary instruction engaged learners in activities that focus attention primarily on words whereas implicit vocabulary instruction occurs when the mind of learners is concentrated elsewhere, such as on comprehending a written text or understanding spoken material (Marzban \& Kamalian, 2013). Even though each approach has its own merits, explicit vocabulary instruction is conventionally considered more effective than implicit instruction directed toward ELL students Incidental vocabulary acquisition occurs only after repeated exposure and results in relatively small gains in the L2 learning (Marzba \& Kamalian, 2013; Rott, 1999; Waring \& Takaki, 2003, Nation, 2001). Explicit vocabulary instruction is especially crucial in learning academic vocabulary. Academic vocabulary words in this study refer to discipline-specific words which are typically unique to individual academic disciplines (Hiebert \& Lubliner, 2008). They are "the lexicon, concepts, and processes related to the content knowledge of a particular academic discipline" (Perrone, 2015 , p. 61). Thus, they can be technical or abstract, and understanding them is essential to building conceptual knowledge in the disciplines in which they are used. In order for learners' academic vocabulary development to be optimized, they need a structured, systematic, and explicit instruction on specific and high-leverage words (Beck \& McKeown, 2007; Beck, McKeown, \& Kucan, 2002).

Previous research has proposed ways of explicit academic vocabulary instruction. The most common approach used in English-as-a-foreign-language (EFL) contexts is to pro- 
vide learners with word lists or glossaries. Coxhead's (2000, cited in Perrone, 2015) seminal Academic Word List (AWL), for example, selects 570 semantic fields that appear most frequently in a wide range of academic texts (Perrone, 2015). Other types of word lists can be in a form of collocation, definition, or first-language (L1) translation (Hsu, 2010; Hsu \& Hsu, 2007; Lien, 2003; Lin, 2009; Marzban \& Kamalian, 2013; Subon, 2016). Teachers usually direct learners' attention to words after reading some passages. Some teachers explain new words and write the words on the board (Solati-Dehkordi \& Salehi, 2016; Sonbul \& Schmitt, 2009). Some give learners explicit vocabulary exercises relevant to the previously studied passage (Guo, 2010). Still some give learners L1 translation and let learners memorize the words (Ho, 2001; Lin, 2009). Although these approaches still result in vocabulary knowledge gain, learners are passive knowledge receivers with this type of instruction.

To increase learners' engagement in vocabulary acquisition, the instruction design in this study focuses on a learner-centered approach that triggers students' active learning. The steps of active explicit vocabulary instruction used in this course were adapted from previous studies (Jack, 2015; Marzano, 2004; Perrone, 2015), including: describe, restate, deepen vocabulary understanding, and revise and refine. In addition, to avoid taking away time from the regular class period, student discussion occurred in an online environment, Facebook, outside class. Instead of focusing on the improvement of learners' reading comprehension, vocabulary size, and academic achievement, which has been investigated thoroughly in previous studies (Chang, 2010; Chuang, 2011; Dai, 2014; Hsu \& Lee, 2007; Kharaghani \& Ghonsooly, 2015; Wang et al., 2015), the present study seeks to understand quantitatively and qualitatively learner perception of this active explicit vocabulary instruction in an EMI course. The following research questions are used to guide this study:

1. What is Taiwanese undergraduate students' overall attitude toward the active vocabulary instruction in an EMI course?

2. What is Taiwanese undergraduate students' perception of the active vocabulary instruction in an EMI course?

3. Do Taiwanese undergraduate students' conceptual knowledge of academic words change before and after the active explicit vocabulary instruction?

\section{RELATED LITERATURE}

\section{Importance of Explicit Vocabulary Instruction}

Extensive research has shown that academic vocabulary plays a critical role in the overall academic success of monolingual English K-12 learners (Bauman \& Graves 2010; McKeown, Beck, \& Sandora, 2012), of English-language learners (ELLs) (Perrone, 2015; Yovanoff, Duesbery, Alonzo \& Tindal, 2005) and English-as-a-foreign-language (EFL) learners (Khezrlou, Ellis, \& Sadeghi, 2017; Masrai \& Milton, 2017; Yunus, Mohamed, \& Waelateh, 2016). It is generally agreed that if ELLs and EFL learners are going to be successful in school, they need vocabulary instruction.
Previous studies investigating vocabulary instruction basically follow two approaches: explicit and implicit. Explicit vocabulary learning engages learners in activities that focus attention primarily on vocabulary whereas implicit vocabulary learning occurs when the mind of learners is concentrated elsewhere. However, Dutro and Moran (2003) pointed out that when L2 learners or ELLs were simply exposed to an English-language rich environment, such as in classrooms, they still cannot develop sufficient language skills for academic success. Solely relying on implicit instruction to facilitate L2 vocabulary acquisition is problematic for several reasons (Sökmen, 1997). First, guessing words in context is likely to be a slow process. Second, students seldom guess the correct meanings. Third, even when students guess words in context, their comprehension may still be low due to insufficient vocabulary knowledge. In order for learners' vocabulary development to be optimized, they need a structured, systematic, and explicit instruction of specific and high-leverage words (Beck \& McKeown, 2007; Beck, McKeown \& Kucan, 2002).

Explicit academic vocabulary instruction is commonly used in ELL and EFL classrooms. Previous studies investigating the effect of academic vocabulary instruction focused on two areas: (a) the impact of vocabulary size and knowledge on student academic writing skills (Flowerdew, 2015; Lee, 2003; Solati-Dehkordi \& Salehi, 2016; Yang, 2015; Yoon \& Hirvela, 2004), and (b) the impact of teaching vocabulary on vocabulary size and reading comprehension (Hsu, 2010; Laufer \& Paribakht, 1998; Subon, 2016). Hsu (2010), for example, examined the effect of direct collocation instruction on Taiwanese English majors' reading comprehension and vocabulary learning. He concluded that the treatment of collocation instruction promoted learners' retention of vocabulary knowledge more than their comprehension. Sonbul and Schmitt (2009) compared vocabulary learning between two conditions: implicit and explicit learning on 40 university students. Under the direct teaching condition, the teacher gave two meanings for each target word, wrote them on the board, and repeated them once. Words under the implicit condition, on the other hand, were deliberately ignored in terms of explicit instruction. They found that direct instruction clearly resulted in lexical gains more than incidental approach.

Although many studies have examined the impact of direct vocabulary instruction on student learning outcome, they focused mainly on quantitative results. In other words, researchers intentionally added vocabulary-learning activities as treatments within an experimental study design to test whether the vocabulary-learning process improved learners' composition scores, vocabulary knowledge, or reading comprehension. Few of them have tried to understand learner perception on direct vocabulary instruction by using qualitative research method.

\section{Explicit Vocabulary Instruction and Active Learning}

While previous research has showed the importance of direct vocabulary instruction, it is crucial to understand the necessary components to include. Explicit vocabulary instructions 
mentioned in previous studies tend to focus on lecture-centered or translation methods (Ghannadi, 2010; Marzban \& Kamakian, 2013; Sonbul \& Schmitt, 2009). In Hsu's study, the direct vocabulary instruction was described as follows: The teacher provided lexical collocation list or the target single-item word list to the students and informed them to form groups to discuss the list first. The student groups were later given another list of the collocation or words with the Chinese equivalences. Each group then composed a sentence using the target word and orally presented their sentences (p.59). Existing studies conducted in Taiwan especially focus on this type of method (Hsu, 2010; Hsu \& Hsu, 2007; Lien, 2003). Kuo and Ho (2012) compared the effects of a word card strategy versus a word list strategy on Taiwanese EFL junior high school students' vocabulary retention. Lu (2004) reported that a bilingual word-list group of $31 \mathrm{EFL}$ students significantly outperformed their counterparts learning through implicit vocabulary learning.

Yet, this word-list method has its limitations. First, academic terminology may not have understandable L1 equivalences. Even if students are given a L1 translation, the translation may not make sense to students. Moreover, this approach tends to emphasize more on the breadth of vocabulary knowledge (Cheng, 2005; Chou, 2011) instead of the depth of knowledge. As mentioned earlier, the acquisition of academic vocabulary is complex and discipline-specific. Increasing learners' vocabulary size may not lead to the increase in their knowledge of words. Previous studies (Qian, 1999, 2002; Shen, 2008) have pointed out that depth of vocabulary knowledge can make a unique contribution to the prediction of reading comprehension levels, in addition to the prediction afforded by vocabulary size. Nassaji (2006) examined the relationship between ESL learners' depth of vocabulary knowledge and their success in deriving word meaning from context. The results revealed that depth of vocabulary knowledge made a significant contribution to inferential success. Simply memorizing academic English words and knowing their Chinese translations may present greater learning challenges to EFL students when learning in EMI courses.

Second limitation of using word list is that, this method emphasizes the teachers' lectures and students' memorization. The students' responsibility is to memorize the words. The teachers' job is to explain the target words or to provide definitions for learners to practice. Although this method still results in vocabulary knowledge gain, learners are passive knowledge receivers. For students in the tech-savvy generation, simply listening to word explanations may not be appreciated due to their familiarity with cutting-edge technology. According to McMahon and Pospisil (2005), millennial students are digital natives. They prefer environments that support multitasking and group activities. This generation is distinguished by their access to technological and collaborative experiences (Roehl, Reddy, \& Shannon, 2013). Thus, implementing an active vocabulary learning opportunity that involves technology and collaboration may be more preferable.

Active learning is an umbrella term for pedagogies focusing on student activity and student engagement in the learn- ing process (Prince, 2004). In other words, activities should be designed to emphasize important learning outcomes requiring thoughtful participation on the part of the student (Prince, 2004). Previous studies proposing effective explicit vocabulary instruction share this perspective. Jack (2015), for example, proposed some instructional principles for effective vocabulary instruction and engaging learners' active learning is one of them. Furthermore, Perrone (2015) suggested that students should discuss the words they are learning. In a pilot study conducted by Zimmerman (1997), 35 ELL students preparing for university entrance were divided into two groups. Students in both groups were instructed in reading, composition, oral language, and academic skills. The only difference in the instruction of the two groups was that the experimental group received interactive vocabulary instruction. The results showed that interactive vocabulary instruction accompanied by course-related reading led to gains in vocabulary knowledge. Finally, Chou (2017) implemented a learner-centered vocabulary instruction on EFL students' academic performance in an EMI course. The results showed that students had a positive attitude toward a learner-centered vocabulary instruction because the interaction process deepened the participants' knowledge of academic words (p.165). Despite positive findings, little research has concentrated on deepening our understanding regarding learner perception of active vocabulary instruction.

\section{METHOD}

\section{Research Design}

This study was carried out with 56 junior students at a Taiwanese university from one course. The students in this particular program will become English teachers. Thus, all courses offered in this department are taught in English. The course on which this study was conducted is a required course, titled "Curriculum Development and Language Education for Educational Purpose." Students were 21 or 22 years old. Since this course was offered in the third year, students in general had taken at least two years of EMI courses previously. The explicit vocabulary instruction was carried out mainly in an online environment using the platform, Facebook. The instructor created a group for this course on Facebook so that students posted their answers and comments. The reason for doing explicit vocabulary instruction online is to save class time. As mentioned, this course is an academic course. The objective of this course is for students to learn the subject matter instead of language per se. Thus, the instructor did not want to spend much time teaching academic words. She wanted to focus on the theories and concepts.

\section{Active Explicit Vocabulary Instruction Procedures}

The steps of active explicit vocabulary instruction used in this course were adapted from previous studies (Jack, 2015; Marzano, 2004; Perrone, 2015). Because teaching principles and procedures mentioned in previous studies focus mainly on K-12 settings, only those suitable for undergraduate students in academic contexts were applied. The steps of explicit vocabulary instruction are described as follows: 
1. Describe and restate: The instructors listed content-specific words (8-10 words) in the up-coming lesson content and asked the students to find the meaning of each word prior to the lesson. The academic words were selected purposefully because they were essential for understanding the main concepts associated with a theory (Nisbet \& Tindall, 2015). The students working in groups found the definitions from the textbook or from Internet sources. They needed to define the words using their own words and then posted their definitions on Facebook. For example, to explain the word "stakeholders," students may define it as "A person who will affect or be affected by the organization's actions and policies and therefore has a responsibility to the organization and interest in its success."

2. Clarify: After posting their answers, each group was required to comment on other groups' definitions and left their comments on Facebook. Students needed to finish finding definitions and commenting before class. The instructor would read the students' definitions and comments so that she knew what words were more confusing or difficult to students. In class, she orally clarified or explained those words using ELL-friendly definitions. The instructor would also use examples when explaining the words. For example, the instructor explained stakeholders as "individuals or an institution that are interested in the school curriculum. They are the one who put into action and can shape the school curriculum implementation. Those individuals can be teachers, parents, and curriculum managers and administrators."

3. Deepen vocabulary understanding: After class, students were asked to re-visit their definitions and decided if they wanted to modify their definitions. They were also required to provide examples for some words to enhance their depth of word knowledge. For example, students wrote "stakeholders are people who are related to the curriculum development, such as school funders, parents, school administrators and community." Students needed to put their final version of word definitions and examples on Facebook. The instructors would mark students' answers as correct or incorrect.

This online active explicit vocabulary instruction was applied in Curriculum Development and Language Education for Educational Purpose for 18 weeks with three coursehours per week. In the first week of the course, participants were informed about the online explicit vocabulary instruction. Next, the instructor spent about 20 minutes of class time guiding the students through the procedures of the online explicit vocabulary instruction.

The instructor posted a new set of terminology, about 4-6 words, when starting a new chapter. Although the instructor only covered three chapters per semester, one chapter contained more academic terms than other chapters. Therefore, the instructor provided two sets of terminology for that particular chapter. As a result, four online explicit vocabulary instructions were completed.

\section{Data Collection and Analysis}

Data were collected through three means. The first data set was an attitude questionnaire asking about student attitudes toward online explicit vocabulary instruction. It was distributed to the participants in the last week of the course. This 6 -point Likert scale questionnaire (with $1=$ strongly disagree and $6=$ strongly agree) consisted of 20 items including two open-ended questions. Since the instructor helped distribute the questionnaires, all of the questionnaires were returned back to the researcher without any loss. The questionnaires were in participants' mother tongue (Mandarin Chinese) and anonymous.

The second data set was from interviews. The researcher also asked the instructor to help her send out invitations for follow-up interviews. Students who were willing to participate in the follow-up interviews could contact the researcher individually. Seven students participated in the follow-up interviews. The interviews were conducted one week after the final week of the semester. The atmosphere of the interview was like an informal conversation about the students' opinions regarding vocabulary instruction. The interviewees were informed about their rights; note-taking and audio recording were used with the interviewees' permissions to collect interview data. The interviews were in the students' first language. The recorded interview data were transcribed verbatim and later translated into English by the researcher. The original and translated transcriptions were presented to the interviewees for member-checking purposes. The interviewees were free to comment on the expressions and translations and make suggestions.

The third data set was from students' online discussions. The changes of word definitions before and after lessons were observed. The purpose of comparing students' definitions before and after lessons was to depict whether participants revise their conceptions or involve some kind of reinterpretation.

Fifty-six questionnaires were collected. The internal consistency level was measured through the Cronbach's alpha analysis and the result was.86. The quantitative results were analyzed using descriptive statistics. The qualitative data were based on the results of the interviews. All follow-up interviews were transcribed verbatim and analyzed using a theme-based approach. In other words, the students' responses were selected and used to provide explanation for the quantitative results. Data collected from the online discussion board were analyzed focusing on the changes in students' posts.

\section{RESULTS \\ Descriptive Statistics Results}

A total of 56 junior-year undergraduates $(\mathrm{M}=10, \mathrm{~F}=46)$ enrolled in the course and participated in this study. To answer the first research question, descriptive results were used to depict the students' attitudes toward active explicit vocabulary instruction. Before presenting descriptive statistics results, principle component analysis was used 
because to identify factors underlying the attitude questionnaire. Initial eigen values indicated that the first three factors explained $36 \%, 19 \%$, and $8 \%$ of the variance respectively. The fourth factor had eigen value just over one and explained $6 \%$ of the variance. Solutions for two, three, and four factors were each examined. The three factor solution which explained $63 \%$ of the variances, was preferred. One item was eliminated because it did not contribute to a simple factor structure. The item "I don't think this online discussion is suitable for me" did not load above.4 on any factor. For the final stage, a principle components factor analysis of the remaining 17 items was conducted, with three factors explaining $65.6 \%$ of the variance. An oblimin rotation provided the best defined factor structure. All items in this analysis had primary loadings over.5. The factor loading matrix for this final solution is presented in Table 1.

Descriptive results are presented according to the three factors. The first one is related to students' thoughts on how this active explicit vocabulary instruction affected their learning outcomes in this course. The overall mean score 4.57 indicates that students had positive attitude toward this method because this method helped them learn the academic subject (Table 2).

The second factor is about the students' views on how this active explicit vocabulary instruction was conducted. At the first glance, the mean score 3.36 seemed to show students' slightly negative attitudes. However, the questions under this factor (except item 12) asked whether students felt it difficult to undergo this method. Thus, this negative attitude indicates that students did not consider participating this active explicit vocabulary instruction difficult.

The third factor is about students' attitudes toward the implementation of this method in an EMI course. The mean score 4.39 indicates that students view positively on this aspect.

In conclusion, students overall had a positive attitude toward this method and considered this method useful in helping them learn in an EMI course. Students also considered this method helpful in their exam performances in three types of questions (items 6-8 in Table 2). When asking how they felt about each step of active explicit vocabulary instruction (items 10-15), students did not think the steps were too difficult to manage. They also showed positive attitudes toward working in groups. They also recommend using this method in other EMI courses.

The descriptive results show that students had positive attitudes toward explicit vocabulary instruction method. Learning academic words explicitly not only helped students understand English textbooks and lectures, but also helped them in exams. In addition, the steps of explicit vocabulary instruction were not too difficult to most of the students. They also recommend using this method in other EMI courses.

Table 1. Pattern matrix (a)

\begin{tabular}{|c|c|c|c|}
\hline \multirow[t]{2}{*}{ Item No. } & \multicolumn{3}{|c|}{ Component } \\
\hline & 1 & 2 & 3 \\
\hline 1 & 0.808 & & \\
\hline 2 & 0.886 & & \\
\hline 3 & 0.842 & & \\
\hline 4 & 0.928 & & \\
\hline 5 & 0.882 & & \\
\hline 6 & 0.767 & & \\
\hline 7 & 0.684 & & \\
\hline 8 & 0.732 & & \\
\hline 9 & & & 0.542 \\
\hline 10 & & 0.749 & 0.371 \\
\hline 11 & 0.502 & & \\
\hline 12 & & 0.877 & \\
\hline 13 & & 0.862 & \\
\hline 14 & 0.363 & 0.600 & \\
\hline 15 & & 0.756 & \\
\hline 16 & & 0.532 & -0.609 \\
\hline 17 & & & 0.709 \\
\hline
\end{tabular}

Extraction Method: Principal Component Analysis. Rotation Method: Oblimin with Kaiser Normalization. a Rotation converged in 9 iterations.

Table 2. Students' attitudes toward the effectiveness of the active explicit vocabulary instruction on their learning outcomes

\begin{tabular}{llcc}
\hline Item No. & Statement & Mean & Standard deviation \\
\hline 1 & I have learned a great deal in this course. & 4.66 & 1.05 \\
2 & This method increases my learning effectiveness. & 4.57 & 1.14 \\
3 & This method helps me preview. & 4.77 & 1.04 \\
4 & Knowing academic words increases my reading comprehension. & 4.82 & 1.05 \\
5 & Knowing academic words increases my understanding of lectures & 4.71 & 0.97 \\
6 & Learning academic words is helpful when I was answering multiple-choice questions & 4.88 & 0.96 \\
7 & in exams. & 4.86 & 0.96 \\
8 & Learning academic words is helpful when I was answering term-definition questions & 4.61 & 1.22 \\
& in exams. & & 3.50 \\
\hline
\end{tabular}


Table 3. Students' views on the instruction procedures

\begin{tabular}{llcc}
\hline Item No. & Statement & Mean & Standard deviation \\
\hline 10 & I need the teacher to provide Chinese definitions for academic words. & 3.18 & 1.56 \\
12 & I like to discuss with group members. & 4.31 & 1.31 \\
13 & Paraphrasing word definitions is difficult. & 3.20 & 1.34 \\
14 & I need the teacher to teach the words in class. & 3.04 & 1.35 \\
15 & Providing examples to elaborate the academic words is difficult. & 3.09 & 1.37 \\
\hline
\end{tabular}

Table 4. Students' attitudes toward the implementation of this method

\begin{tabular}{llcc}
\hline Item No. & Statement & Mean & Standard deviation \\
\hline 9 & Explicit vocabulary instruction did not help me learn in an EMI course. (reversed) & 4.98 & 1.04 \\
16 & Often time, I did not understand the lectures in English. (reversed) & 4.07 & 1.22 \\
17 & This method should be used in more EMI courses. & 4.11 & 1.25 \\
\hline
\end{tabular}

\section{Interview Results}

Follow-up interviews were conducted after the questionnaires were collected to explore students' perception of the active explicit vocabulary instruction approach. Seven students voluntarily participated in the interviews. Students' answer were organized and presented in the same order of quantitative results using the three factors: the effectiveness of this method on learning performance, the instruction procedures, and the implementation of this method in EMI courses.

\section{Comments on the Effectiveness of Active Explicit Vocabulary Instruction}

When being asked which aspect they thought this method helped them learn in this academic course, students all agreed that it was the collaboration and self-learning parts. Jude said that when they were asked to find definitions by themselves, they needed to think about the definitions and wrote them down in their own words. They can remember those words better. Yin enjoyed paragraphing and creating examples for this prolonged the retention of words. Emma further elaborated:

I liked to discuss with my group members. Even though people had different understandings of the word meanings, this stimulated me to think. When I read other groups' definitions, I also can compare my own understanding with others.

Some students appreciated being requested to preview words before class. Max, for example, talked about the preview part of this method:

I thought finding the academic words before class was helpful. When we discussed those words, we got a sense of some key concepts of the up-coming chapter or content. When I was in class, I paid more attention to those points.

Emma added to Max's opinions explaining that

Finding academic words helped me preview. As a result, I had a better understanding of what I knew and what I did not. When listening to the lecture, I confirmed my understanding or correct my misunderstanding. It made listening to English lectures or the teacher's explanations much easier.

\section{Comments on instruction procedures}

Further, the students were asked to comment on the instruction processes, including finding definitions, posting online, the teacher's feedback and explanations in class, and revising. Two parts were mostly mentioned in the interviews: (a) teacher's explanations in class and feedback online, and (b) revising. Five out of seven students mentioned that the teacher's feedback to their definitions could be more explicit. This can be viewed from two circumstances. The first circumstance is about the way the teacher provided clarification in class. As mentioned earlier, the teacher read students' definitions and chose some words for clarification in class. One student did not seem to notice that the teacher clarified word definitions in class. She described, "I did not feel that the teacher went through the academic words in class. It seemed to me that the teacher just lectured the content." However, other students explained how the teacher clarified those words in her lecture. Wang, for example, said:

The teacher orally explained word definitions in the lectures. If we still did not understand the word, she would use examples to help us understand, for example, the words "inductive" and "deductive."

Ivy added:

The teacher would not explain all the terms. Only those we were confused in our online posts. She used examples to help us understand the meanings [of the words].

The second circumstance was related to how the teacher corrected the students' definitions online. Even though the teacher marked the incorrect ones in red after students posted their final definitions, she did not give students "correct" and "official" definitions. Students felt that they still could not understand why their definitions were incorrect. Thus, six out of seven students expressed their desire for "correct" and written definitions from the teacher. As Jude mentioned:

I hoped that she [the teacher] can give us the definitions after our final versions. Sometimes she marked red if the definitions were not correct. However, we did not know what part was not correct, why it was not correct. It became very confusing.

Yin agreed by saying that

It is good that the teacher read our definitions and made marks. However, I hoped that she can give us her defi- 
nitions...written down not just orally explained...We asked her when our answers were marked red, but she often said, "it's too vague" or "you need to be more specific." Final written definitions from the teacher would be appreciated.

However, Emma did not consider this necessary. She argued that

I don't think a final definition is necessary because the teacher already told us in her lecture. When I was in class, I compared my definition with the teacher's. Wrote down the differences and added the teacher's explanation and examples in my notebook...If the teacher gave so call final or teacher's definitions, the whole self-learning processes would be meaningless because students would rely on the teacher's definitions and would not make effort in group discussions.

The other part the students commented is the revising section. After the class, students were required to modify their definitions and provide examples to demonstrate their understanding. Students in the interview expressed their frustration during this step. Jude mentioned that the teacher would not allow them to create the same examples provided in the class. Therefore, they needed to create their own examples and it was difficult. In addition, when reviewing their definitions, they tended to argue with their group members because everyone might have had different understandings of the definitions. They sometimes became more confused after they read others' comments and listened to the teacher's explanations.

\section{Comments on the Implementation of Active Explicit Vocabulary Instruction in EMI Courses}

Finally, students were asked about their overall perception of the implementation of this method. All students highly valued the method. Students' opinions were into two parts: explicit vocabulary learning and active, a.k.a. learner-centered, learning. Students highly recommended teachers implemented academic vocabulary teaching in other EMI courses, especially for academic subjects. Some students mentioned that teachers in their English-language classes would teach vocabulary explicitly. However, not many teachers would teach vocabulary in academic courses. As Max described, "It is strange that vocabulary learning was heavily emphasized in English-language classes but not in academic courses where we [EFL students] actually needed most to understand academic contents."

Students also highly recommended using this learner-centered teaching method when learning vocabulary. Emma compared this method with the conventional direct vocabulary instruction in her English-language classes. She thought this method was more effective in helping her learn vocabulary than a teacher-centered method.

If teachers only give us word list with definitions, we will simply memorize those definitions. If we can discuss first, we can think about the words from different viewpoints. That helps us understand words.

Jude and other students also felt that they learned better and memorized words better if they can learn by themselves first. Jude added on Emma's point commenting that
Just like my English teacher, she teaches vocabulary words and explains meanings one by one. She even printed out word list with clear definitions for us. But I am lazy. I usually just glanced the word list and set it aside. I may try to memorize those words right before midterms or finals but that is all. Those word lists do not help me much.

To sum up, the seven students overall appreciated this active explicit vocabulary instruction approach. The most appreciated part was when students are given opportunities to define academic words by themselves and discuss with their group members. However, most students also expressed their needs for correct or "teacher-proved" answers. Without an official definition from the teacher, the students will feel a sense of insecurity.

\section{Changes in Conceptual Knowledge of Academic Terminology}

Last but not least, changes in student posts were observed. A total of 80 posts were collected. The class was divided into 10 groups. Each group posted definitions at 2 points, before and after the lessons. Students were asked to participate in vocabulary learning four times. As a result, 80 posts were found. Students' definitions were compared to see if they made any change when they defined the words by themselves and after reading others' comments and the teacher's explanation in class. Among the 80 posts, only 6 posts showed that students changed their definitions from incorrect to correct ones. For example, one group defined "open enrollment" as "Students can choose from various available options, deciding which school/department/course to attend" to "Students can choose whether they want to add or drop the class at any time." None was found from correct to incorrect. However, almost all posts were either all correct or all incorrect. Surprisingly, even if students made changes after lessons, their answers remained incorrect in most of the cases.

\section{DISCUSSION AND CONCLUSION}

This study explores EFL students' perceptions of active explicit vocabulary learning. Quantitative and qualitative results are consistent with each other showing that students are positive about actively engaging in vocabulary learning. Overall, these quantitative analyses indicate that three distinct factors are underlying students' attitude toward active explicit vocabulary instruction. Students' positive attitude is most obvious when the students thought that this method helped them improve their learning outcomes, including increasing comprehension in reading English-language textbooks and understanding English-medium lectures. They also thought that engaging in learning vocabulary helped their performance in the exams. The results correspond to previous studies showing that students valued being active (Machemer \& Crawford, 2007). Students also valued the roles and responsibilities they were given. This active learning opportunity, which is different from a teacher-centered approach used in other courses, is highly appreciated by the students. The positive attitudes and perceptions demonstrate what Prince (2004) has pointed out; that is, the effectiveness 
of the active learning approach helps students prolong their attention span during lectures and promote students' engagement (p.3). The students thought it especially important when learning in an EMI course for an academic subject. The results show that the students generally valued this method.

Moreover, the interview results show that students enjoyed working in groups. This corresponds to the quantitative result showing that the students enjoyed working in groups and did not consider the cooperative tasks difficult to accomplish. It is also surprising to see that the students did not show negative experiences such as time consuming or pressured workload in their interviews as sometimes mentioned in previous studies (Chou, 2017; Livingstone \& Lynch, 2000). This may be due to a careful design from the instructor. As mentioned before, the instructor chose 8-10 words for groups to work on. This amount of vocabulary is not too overwhelming for students to handle.

However, the students' performances from group work are disappointing as shown in the changes of the word definitions. This may be because in cooperative learning, the students are individually responsible for their own as well as the group's learning. The students did value having the cooperative learning opportunity, however, did not want to be responsible to the group for learning (Machemer \& Crawford, 2007). To be more specific, some students may have better understanding of vocabulary knowledge after the lectures as they self-reported in the questionnaire. They did not want to provide their answers to contribute to the group final discussion results. As a result, some groups hardly changed their answers before and after the course. One solution to this problem is to grade group performances. As mentioned in Machemer and Crawford's study (2007), any activity that directly relates to exam performance will be valued. If an instructor wants to make cooperative learning more effectively, she or he should consider making group discussion results as one part of the students' overall grades.

In some other cases, students generally cannot change their incorrect answers. Their answers remained incorrect even though they tried to change their answers. This result contradicts previous studies showing that active learning results gains in learner performance (Chou, 2017; Freeman et al., 2013; Zimmerman, 1977). This result may be due to the ineffectiveness of the instructor's implicit explanations. As mentioned in the interviews, the students generally did not think that the teacher's oral explanations in class were sufficient and effective. They expected the teacher could give them correct answers after the instruction. This again indicates that implicit vocabulary instruction may not be as effective as explicit vocabulary instruction (Dutro \& Moran, 2003; Sökmen, 1997). For these EFL students, explicit explanations from teachers may be essential to result in vocabulary knowledge gains.

\section{IMPLICATIONS AND LIMITATIONS}

Some educational implications can be given based on the results of the present study. First, an active vocabulary learning method is highly recommended. Many Taiwanese students are passive learners. They are accustomed to coming into the class without preparation and simply sitting and listening to the lecture. This type of learning habit may not be a problem if the lectures are in their mother tongue. However, they face a great difficulty when studying in EMI courses. Active learning gives them an opportunity to take responsibilities in their own learning. Once they have an idea of the content for the up-coming class, they are able to understand English lectures better. Second, explicit vocabulary teaching is necessary. Even though active learning increases student engagement, it does not automatically lead to changes of vocabulary knowledge. Explicitly explaining academic words seems to be necessary to make changes for student cognitive gain. Third, online environment can be a useful interface to foster active and cooperative learning. However, teachers should carefully choose meaningful activities that require students to synthesize, analyze and evaluate information. Pedagogical methods also need to be cautiously designed to connect online learning activities with in-class ones.

This study, however, is subject to a few limitations. First, the scope of this study is relatively small and hence has limited generalizability. More studies conducted in different contexts and among participants are recommended. Second, student performance in this study merely looks at the changes of word definitions before and after the instruction. Various aspects can be analyzed to depict whether active learning enhance student academic performance. Finally, this study uses a case study involving one classroom to depict student perceptions. Experimental studies comparing learning outcome between student-centered and teacher-centered approaches are recommended for future study.

\section{REFERENCES}

Anjomshoa, L., \& Zamanian, M. (2017). The effect of vocabulary knowledge on reading comprehension of Iranian EFL learners in Kerman Azad University. International Journal on Studies in English Language and Learning, 2(5), 90-95.

Baumann, J. F., \& Graves, M. F. (2010). What is academic vocabulary? Journal of Adolescent \& Adult Literacy, 54(1), 4-12.

Beck, I. L., \& McKeown, M. G. (2007). Increasing young low-income children's oral vocabulary repertories through rich and focused instruction. The Elementary School Journal, 107(3), 251-271.

Beck, I. L., McKeown, M. G., \& Kucan, L. (2002). Bringing words to life. New York: The Guilford Press.

Chang, Y. -Y. (2010). English-medium instruction for subject courses in tertiary education: Reactions from Taiwanese undergraduate students. Taiwan International ESP Journal, 2(1), 55-84.

Cheng, Y. -H. (2005). Effectiveness of using vocabulary glosses to enhance technological university business and engineering majors' EFL reading comprehension and vocabulary learning (Unpublished master thesis), National Kaohsiung First University of Science and Technology, Kaohsiung, Taiwan. Chia, Johnson, Chia and Olive (1999)

Chou, P. (2011). The effects of vocabulary knowledge and background knowledge on reading comprehension of 
Taiwanese EFL students. Electronic Journal of Foreign Language Teaching, 8(1), 108-115.

Chou, I.-C. (2017). The effects of explicit academic vocabulary instruction in an English-medium Educational Psychology on EFL learners' content knowledge. The Asian ESP Journal, 13(2), 144-179.

Chuang, H.-C. (2011). The effects of explicit reading program on vocabulary acquisition of EFL junior high school students in Taiwan (Unpublished master thesis). Kaohsiung Normal University, Kaohsiung, Taiwan.

Dai, J. R. (2014). The Effects of Extensive Reading on Taiwanese College Students' Reading Comprehension and Learning Motivation (Unpublished master thesis). Chung Yuan Christian University, Taoyuan, Taiwan.

Dutro, S., \& Moran, C. (2003). Rethinking English language instruction: An architectural approach. In G. Garcia (Eds.), English learners: Reading the highest level of English literacy (pp. 227-258). Newark, DE: International Reading Association.

Evans, S., \& Green, C. (2007). Why EAP is necessary: A survey of Hong Kong tertiary students Journal of English for Academic Purposes, 6(1), 3-17.

Flowerdew, L. (2015). Corpus-based research and pedagogy in EAP: From lexis to genre. Language Teaching, 48(1), 99-116.

Freeman, S., Eddya, S. L., McDonougha, M., Smithb, M. K., Okoroafora, N., Jordta, H., \& Wenderoth, M. P. (2013). Active learning increases student performance in science, engineering, and mathematics. PNAS, 111(23), 8410-8415.

Ghannadi, M. (2010). Interventionist (explicit and implicit) versus non-interventionist (incidental) learning of phrasal verbs by Iranian EFL learners (Unpublished master thesis). Allameh Tabataba'i University, Tehran, Iran.Guo, 2010)

Hiebert, E. H., \& Lubliner, S. (2008). The nature, learning, and instruction of general academic vocabulary. In A.E. Farstrup \& S.J. Samuels (Eds.), What research has to say about vocabulary instruction (pp. 106-129). Newark, DE: International Reading Association.

Ho, W. C. (2001). A Study on teacher vocabulary explanation in vocational high school EFL classrooms (Unpublished master thesis). National Changhua University of Education, Changhua, Taiwan.

Hsieh, S. -H., \& Kang, S. -C. (2007). Effectiveness of English-medium instruction of An engineering course and strategies used by the teacher. [Online] Available: http:// ctld.ntu.edu.tw/rp/95_01.pdf (March 6 $\left.{ }^{\text {th }}, 2015\right)$

Hsu, J.-Y. (2010). The effects of collocation instruction on the reading comprehension and vocabulary learning of Taiwanese college English majors. The Asian EFL Journal Quarterly, 12(1), 47-87.

Hsu, J.-Y., Hsu, L.-C. (2007) Teaching lexical collocations to enhance listening comprehension of English majors in a technological university of Taiwan. Soochow Journal of Foreign Languages \& Cultures, 24, 1-32.

Hsu, Y.-Y., \& Lee, S.-Y. (2007). Extensive reading and EFL junior college students in Taiwan. [Online] Available: http://www-o.ntust.edu.tw/ syying.lee/publications/ Hsu_Lee_SELL2007.pdf (March 10 $\left.{ }^{\text {th }}, 2017\right)$

Jack, A. (2015). Effective direct vocabulary instruction to meet the focus of the common core standards. The Open Communication Journal, 9, 39-43.

Kharaghani, N., \& Ghonsooly, B. (2015). The impact of vocabulary knowledge on reading comprehension ability of Iranian English learners receiving reciprocal teaching and cooperative grouping intervention program. International Journal of Research Studies in Education, 4(3), 47-46.

Khezrlou, S., Ellis, R., \& Sadeghi, K. (2017). Effects of computer-assisted glosses on EFL learners' vocabulary acquisition and reading comprehension in three learning conditions. System, 65, 104-116.

Knudsen, S. S., \& Westbrook, P. (2013). Preparing students and lectures for English medium instruction at the university of Copenhagen. [Online] Available: http://conference.pixel-online.net/ICT4LL2013/common/download/Paper_pdf/011-CLI01-FP-Knudsen-ICT2013.pdf (March 19 $\left.9^{\text {th }}, 2015\right)$

Kojic-Sabo, I., \& Lightbown, P. M. (1999). Students' approaches to vocabulary learning and their relationship to success. The Modern Language Journal, 83, 176-192.

Kuo, Y., \& Ho, H.-Y. (2012). Effects of word card strategy versus word list strategy on Taiwanese EFL junior high school students' vocabulary retention. Electronic Journal of Foreign Language Teaching, 9(1), 26-45.

Laufer, B., \& Paribakht, T. S. (1998). The relationship between passive and active vocabularies: Effects of language learning context. Language Learning, 48(3), 365391.

Lee, S. H. (2003). ESL learners' vocabulary use in writing and the effects of explicit vocabulary instruction. System, 31(4), 537-561.

Lien, H.-Y. (2003). The effects of collocation instruction on the reading comprehension of Taiwanese college students (Unpublished doctoral dissertation). Indiana University of Pennsylvania, Pennsylvania.

Lin, Y.-P. (2009). Enhancing EFL learners' English reading proficiency through collocation instruction. English Teaching \& Learning, 33(1), 37-71. http://dx.doi. org/10.6330/ETL.2009.33.1.02

Lu, C. (2004). The effects of reading articles and memorizing word lists on EFL high school students' reading and vocabulary abilities (Master thesis). National Taiwan Normal University, Taiwan.

Machemer, P. L., \& Crawford, P. (2007). Student perceptions of active learning in a large cross-disciplinary classroom. Active Learning in Higher Education, 8(1), 9-30.

Marzano, R. J. (2004). Building background knowledge for academic achievement. Alexandria, VA: Association for Supervision and Curriculum Development.

Marzban, A., \& Kamalian, K. (2013). Effects of implicit versus explicit vocabulary instruction on intermediate EFL learners' vocabulary knowledge. ELT Voices-India, 3(6), 84-95. 
Masrai, A., \& Milton, J. (2017). Recognition vocabulary knowledge and intelligence as predictors of academic achievement in EFL context. TESOL International Journal, 12(1), 128-142.

Masrai, A., \& Milton, J. (2018). Measuring the contribution of academic and general vocabulary knowledge to learners' academic achievement. Journal of English for Academic Purposes, 31, 44-57.

McKeown, M. G., Beck, I. L., \& Sandora, C. (2012). Direct and rich vocabulary instruction needs to start early. In E. J. Kame'enui \& J. F. Baumann (Eds.), Vocabulary instruction: Research to practice (pp. 17-33). New York, NY: Guilford Publications, Inc.

McMahon, M., \& Pospisil, R. (2005). Laptops for a digital lifestyle: Millennial students and wireless mobile technologies. Ascilite Conf., Brisbane, Australia, 421-431.

Nassaji, H. (2006). Vocabulary knowledge and L2 learners' lexical inferencing strategy use and success. The Modern Language Journal, 90(3), 387-401. http://dx.doi org/10.1111/j.1540-4781.2006.00431.x

Nation, I. S. P. (2001). Learning Vocabulary in Another Language. Cambridge: Cambridge University Press.

Nisbet, D. L., \& Tindall, E. R. (2015). A framework for explicit vocabulary instruction with English language learners, Kappa Delta Pi Record, 51(2), 75-80.

Perrone, M. (2015). The development of academic vocabulary in K-12 ELLs through explicit, systematic pedagogy: A multifaceted approach. NYS TESOL Journal, 2(1), 60-69.

Prince, M. (2004). Does active learning work? A review of the research. Journal of Engineering Education, 93(3), $1-9$.

Qian, D. D. (1999). Assessing the roles of depth and breadth of vocabulary knowledge in reading comprehension. Canadian Modern Language Review, 56(2), https://doi. org/10.3138/cmlr.56.2.282

Qian, D. D. (2002). Investigating the relationship between vocabulary knowledge and academic reading performance: An assessment perspective. Language Learning, 52(3), 513-536. http://dx.doi.org/10.1111/1467-9922.00193

Richards, J. C. (2002). Teaching vocabulary. In J. C. Richards, \& A. W. Renandya (Eds.), Methodology in Language Teaching: An Anthology of Current Practice (pp.255-257). Cambridge: Cambridge University Press.

Roehl, A., Reddy, S. L., \& Shannon, G. J. (2013). The flipped classroom: An opportunity to engage millennial students through active learning strategies. JFCS, 105(2), 44-49.
Rott, S. (1999). The effect of exposure frequency on intermediate language learner's incidental vocabulary acquisition and retention through reading. Studies of Second Language Acquisition, 21, 589-619.

Shen, Z. (2008). The roles of depth and breadth of vocabulary knowledge in EFL reading performance. Asian Social Science, 14(2), 135-137.

Solati-Dehkordi, S. A., \& Salehi, H. (2016). Impact of explicit vocabulary instruction on writing achievement of upper-intermediate EFL learners. International Education Studies, 9(4), 141-154.

Sonbul, S., \& Schmitt, N. (2009). Direct teaching of vocabulary after reading: is it worth the effect? ELT Journal, 64(3), 253-260. doi:10.1093/elt/ccp059

Subon, F. (2016). Direct vocabulary instruction: The effects of contextualized word families on learners' vocabulary acquisition. 6th International Research Symposium in Service Management, August 2015, Kuching, Malaysia, 11-15.

Sökmen, A. (1997). Current trends in teaching second language vocabulary. In N. Schmitt \& M. McCarthy (Eds.), Vocabulary: Description, Acquisition, and Pedagogy (pp. 237-257). Cambridge: Cambridge University Press.

Waring, R., \& Takaki, M. (2003). At what rate do learners learn and retain new vocabulary from reading a graded reader? Reading in a Foreign Language, 15(2), 130-163.

Wang, B.T., Teng, C.W., \& Chen, H.T. (2015). Using iPad to facilitate English vocabulary learning. International Journal of Information and Education Technology, 5(2), 100-104.

Yovanoff, P., Duesbery, L., Alonzo, J., \& Tindal, G. (2005). Grade-level invariance of a theoretical causal structure predicting reading comprehension with vocabulary and oral reading fluency. Educational Measurement: Issues and Practice, 24(3), 4-12.

Yunus, K., Mohamed, M., \& Waelateh, B. (2016). The breadth of receptive vocabulary knowledge among English major university students. Journal of Nusantara Studies, 1(1), 7-17.

Yang, M.-N. (2015). A nursing academic word list. English for Specific Purposes, 37, 27-38.

Yoon, H., \& Hirvela, A. (2004). ESL student attitudes toward corpus use in L2 writing. Journal of Second Language Writing, 13, 257-283.

Zimmerman, C. B. (1997). Do reading and interactive vocabulary instruction make a difference? An empirical study. TESOL Quarterly, 31(1), 121-140. 